\title{
Humanitarismo (re)vestido no dispositivo moda: entre apropriação e mercantilização
}

Larissa Almada é designer. Professora dos bacharelados em Negócios da Moda e Design de Moda da Universidade Anhembi Morumbi. Doutora em Design pela Universidade Anhembi Morumbi (SP). Mestre em Design de Comunicação de Moda pela Universidade do Minho (Portugal) e Graduada em Design de Moda pelo Senai/CETIQT (RJ). Pesquisa articulações produzidas no dispositivo moda por enunciados, consumo, vestíveis e corpos.

<larissa_almada@yahoo.com.br > ORCID: 0000-0002-3149-2349
Resumo O século XX consolida mudanças no âmbito político-econômico-social mundial que revelam uma atmosfera tomada pela racionalidade neoliberal, onde o mercado dita as regras. Uma das características deste contexto é a mercantilização de diversas instâncias da vida, entre as quais os direitos humanos. Com atenção ampliada para as crises humanitárias, o humanitarismo se torna uma das variáveis fortalecidas nos dispositivos - fatores sociais que fazem operar diagramas de poder na produção de subjetividade. A moda, campo desta investigação, é considerada um dos dispositivos que delineia os modos de ser, pensar e agir desta época. 0 objetivo deste artigo é discutir a captura e uso de questões humanitárias pelo dispositivo moda. De caráter qualitativo, o estudo é desenvolvido por meio de revisão teórica, além de observação documental com revisão bibliográfica e iconográfica, a partir da análise crítica do discurso. As articulações indicam que o humanitarismo é um relevante recurso do dispositivo moda no contexto neoliberal, que, em tempos de revisão de valores, vale-se de apelos humanitários como tática para sua própria manutenção.

Palavras chave Design, Dispositivo Moda, Humanitarismo, Mercantilização. 


\section{Humanitarianism (re)dressed in the fashion dispositive: between appropriation and marketization}

Cristiane Mesquita é psicanalista. Professora e pesquisadora do PPG Design da Universidade Anhembi Morumbi. Doutora e Mestre em Psicologia pelo Núcleo de Estudos da Subjetividade - PUC-SP. Pós-Doutorado no Departamento de Artes da Goldsmiths, University of London. Investiga processos de criação e subjetivação; interações entre corpos, roupas e artefatos; clínica ampliada e produção de sofrimento e saúde psíquica; transversalidades entre psicanálise, filosofia, arte contemporânea, política e design. <cfmesquita@anhembi.brr >

ORCID: 0000-0001-6860-0676
Abstract The twentieth century consolidates changes in the political-economic-social world which reveal an atmosphere taken by neoliberal rationality, where the market dictates the rules. One of the characteristics of this context is the commercialization of diverse instances of life, including human rights. With increased attention to humanitarian crises, humanitarianism becomes one of the strengthened variables in the dispositives - social factors that make power diagrams operate in the production of subjectivity. Fashion, the field of this investigation, is considered one of the dispositives that outlines the ways of being, thinking and acting of this time, in a specially strengthened way. The general objective of this article is to discuss the capture and use of humanitarian issues by the fashion dispositive. Qualitative in nature, the study is developed through theoretical review, documentary observation with bibliographic and iconographic revision, based on the critical analysis of the discourse. The articulations indicate that humanitarianism is a relevant resource of the fashion dispositive in the neoliberal context, which, in times of revision of values, uses humanitarian appeals as a tactic for its own maintenance.

Keywords Design, Fashion Dispositive, Humanitarism, Marketization.

Humanitarismo (re) vestido en el dispositivo moda: entre la apropiación y la mercantilización

Resumen El siglo XX consolida cambios en el mundo político-económico-social que revelan un ambiente tomado por la racionalidad neoliberal, donde el mercado dicta las reglas. Una de las características contextuales es la mercantilización de diferentes instancias de la vida, incluidos los derechos humanos. Con una mayor atención a las crisis humanitarias, el humanitarismo se convierte en una de las variables fortalecidas en los dispositivos - factores sociales que hacen que los diagramas de poder operen en la producción de subjetividad. La moda, nuestro enfoque aquí, es considerada uno de los dispositivos que perfila las formas de ser, pensar y actuar de esta época. El propósito de este artículo es discutir la captura y el uso de problemas humanitarios por parte del dispositivo moda. Este estudio es cualitativo, desarrollado a través de revisión teórica y observación documental, con revisión bibliográfica e iconográfica, basada en el análisis crítico del discurso. Las articulaciones indican que el humanitarismo es un recurso importante del dispositivo moda en el contexto neoliberal, que, en tiempos de revisión de valores, utiliza los llamamientos humanitarios como táctica para su propio mantenimiento.

Palabras clave Diseño, Dispositivo Moda, Humanitarismo, Mercantilización. 


\section{Introdução}

A segunda metade do século XX traz uma série de mudanças no contexto político-econômico-social global. Após a Segunda Guerra Mundial, diante das crises e constantes reformas, afloraram novas forças sob a forma de controles sutis, não mais os confinamentos densos das sociedades disciplinares ${ }^{1}$, forças mais visíveis cuja operação se dava por enquadramentos definidos e rígidos (DELEUZE, 1992).

É importante mencionar, que o diagrama que se estabelece pelo cruzamento dessas forças - seja nas sociedades disciplinares ou nas sociedades de controle - é compreendido como "dispositivo" ", conceito proposto pelo filósofo francês Michel Foucault para descrever variáveis que produzem subjetividades em determinada época, ou seja, modos de ser, de pensar, de agir. Neste artigo, a moda é considerada um dispositivo, tendo em vista que além de orientar o vestir e o consumir, delineia modos de viver.

No entanto, diferentemente do que ocorria no contexto disciplinar, nas sociedades de controle ${ }^{3}$ os efeitos dos dispositivos revelam uma atmosfera tomada pela racionalidade neoliberal. A partir da década de 1980, essa racionalidade torna-se pensamento preponderante nas práticas governamentais, com articulações pautadas pelo mercado. Pela ótica neoliberal, o mercado é um regulador socioeconômico que dita as regras e controla o modus operandi da sociedade. Ou seja, nas sociedades de controle e no contexto neoliberal, as modulações que orientam a construção dos modos de vida são advindas, predominantemente, do mercado.

Uma das características que surgem nesse contexto é a mercantilização de diversas instâncias da vida, como o próprio corpo. Atravessados pela lógica de compra e venda e por ideias de juventude e envelhecimento, os corpos são modelados no dispositivo moda se pensarmos no aparato de vestuários e acessórios que comprimem silhuetas, delineiam as curvas, adequando-os às formas vigentes. Ou seja, a aparência é um dos fatores que o dispositivo moda mercantiliza.

No entanto, esse panorama de mercantilização amplia-se ao considerarmos que, desde o fim dos anos 1970, a sociedade encontra-se na terceira fase do consumo, denominada "hiperconsumo", em que os sujeitos desejam os objetos para reconhecer-se e conectar-se com o mundo, para além da modelação de seus corpos (LIPOVETSKY, 2007). Nesse sentido, outras instâncias aparecem mercantilizadas, como questões relativas à saúde, ao feminismo, aos aspectos raciais que, capturados pelo dispositivo moda, levam seus discursos para campanhas de moda e o design de roupas e acessórios.

Neste trabalho, interessa-nos a mercantilização que atinge os direitos humanos. Com o crescente interesse pelo desenvolvimento humano desde os anos 1980, cidadãos, entidades, instituições e empresas passaram a se mobilizar e promover ações permeadas pelo senso humanitário, como campanhas de combate à fome, de auxílio aos que sofrem com a seca, com a falta de educação, com a ausência de moradia, com a falta de acesso à saúde, entre outras. Desde então, as imagens de dor e sofrimento permeiam aspec- 
tos da cultura contemporânea e definem músicas, estilos de vida, moda e muitas áreas mercantis, que no contexto neoliberal transformam direitos humanos em mercadorias lucrativas.

Com base nesse panorama, este artigo pretende problematizar a captura e uso de questões humanitárias pelo dispositivo moda no contexto das sociedades de controle pautadas pelo mercado segundo a ótica da racionalidade neoliberal. Para melhor compreensão do tema, vale reforçar que a moda, neste trabalho, inclui design de moda, mas não se restringe a isso: implica um lugar de transversalidades e interação entre vestíveis, usuários e fatores mercadológicos no contexto da produção de subjetividade.

O texto inicia-se com um breve histórico sobre o humanitarismo, em seguida destacam-se questões práticas de mercantilização. Por fim, elucida-se uma articulação entre dispositivo moda e o engajamento com causas sociais. De caráter qualitativo, o estudo é desenvolvido por meio de revisão teórica, coleta e observação documental com revisão bibliográfica e iconográfica, a partir da análise crítica do discurso.

\section{Um breve histórico sobre o humanitarismo}

24 de junho de 1859. Solferino, Itália. Uma batalha entre os exércitos da França e Áustria resulta em cerca de 40.000 mortos, dos quais metade não teve atendimento pelas forças armadas, dada a enorme quantidade de feridos para poucos médicos.

Nesse mesmo dia, o empresário suíço Henry Dunant desembarcava em Solferino à procura do Imperador francês Napoleão III, para tratar de questões empresariais. Diante dos acontecimentos, Dunant abandona o intuito de sua viagem, e por dias dedica-se a ajudar na assistência aos feridos com o envolvimento da população local. Segundo o pesquisador grego Costas Douzinas (2007), o humanitarismo surge nesse contexto, depois de o "bom samaritano", como Dunant ficou reconhecido internacionalmente, ter testemunhado o massacre.

Henry Dunant fundou o Comitê Internacional da Cruz Vermelha e articulou junto à esfera governamental suíça ações políticas que resultaram na primeira convenção em Genebra, quando foram assinados diversos acordos pela proteção de envolvidos nos contextos de guerra, que mais tarde foram formatados pela criação do Direito Internacional Humanitário (DIH), no qual estão regulamentados quesitos aplicáveis durante conflitos armados, determinando métodos e meios de guerra aceitáveis e estabelecendo os direitos de combatentes, civis e militares (DEYRA, p.14, 2001), como o alívio da fome e auxílio médico a feridos, doentes ou prisioneiros de guerra, e a civis não envolvidos nos embates armados, mas que estão no contexto.

Enquanto o DIH era desenvolvido, sistematizavam-se os Direitos Humanos (1948) $)^{4}$. Instituída após a Segunda Guerra Mundial, a Declaração Universal dos Direitos Humanos (DUDH) consta de trinta artigos, entre os 
quais destacam-se o Artigo 25: "Toda pessoa tem direito a um nível de vida suficiente para lhe assegurar e à sua família a saúde e o bem-estar, principalmente quanto à alimentação, ao vestuário, ao alojamento, à assistência médica e ainda quanto aos serviços sociais necessários, e tem direito à segurança no desemprego, na doença, na invalidez, na viuvez, na velhice ou noutros casos de perda de meios de subsistência por circunstâncias independentes da sua vontade" (ONU, 1948, s/p).

Embora algumas normas do DIH e da DUDH sejam similares, eles são instrumentos diferentes, principalmente quanto ao contexto em que são aplicáveis. Ao contrário do Direito Internacional Humanitário, a normativa que rege os Direitos Humanos "aplica-se em tempo de paz, e muitas das suas disposições podem ser suspensas durante um conflito armado" (ICRC, 1998, s/p). É relevante que consideremos a relação entre o DIH e os Direitos Humanos (DH), pois os DH são muitas vezes utilizados para respaldar intervenções humanitárias, o que resulta no alargamento contextual do humanitarismo. Isso se nota com maior clareza a partir da década de 1980, quando agências e empresas humanitárias, buscando conciliar prioridades dissonantes e justificar escolhas políticas, passam a se apropriar dos princípios dos Direitos Humanos em contextos que não os de guerras (DOUZINAS, 2007; SOUZA, 2013).

Observa-se então, o surgimento de uma lógica de humanitarismo associado aos Direitos Humanos. O novo humanitarismo (DOUZINAS, 2007; SOUZA, 2013) expressa interesse pela assistência em diversas instâncias, para além das situações de guerra, diante das falhas nas políticas públicas dos Estados, como àquelas relacionadas à fome e aos desastres naturais. De acordo com o antropólogo Bernard Hours (2008, s/p), diversos cidadãos, entidades, instituições e empresas passam a se mobilizar e promover inúmeras ações permeadas e/ou revestidas pelo senso humanitário, como campanhas de doação de pratos de comida, de auxílio aos que sofrem com a seca, de doação de roupas e medicamentos, entre outras. Ou seja, a ideia de humanitarismo, que inicialmente focava no ambiente de guerra e era conduzida por entidades sem fins lucrativos, como o Comitê Internacional da Cruz Vermelha, expande-se a partir de outros agentes de interesse, como empresas, e passa a abarcar diversos aspectos da vida. Vale pontuar que o conceito de humanitarismo passar a ser ressignificado não no âmbito da lei - uma vez que o Direito Internacional Humanitário (DIH) deixa clara a sua delimitação ao contexto de batalhas armadas - mas no âmbito das práticas do dia-dia de civis, empresas e entidades organizadas. 


\section{Mercantilização dos direitos humanos: empresas e a responsabilidade social on demand}

A década de 1980 é um período marcante na ampliação das questões humanitárias. Esse movimento se fez muito atrelado à racionalidade neoliberal que tomava as sociedades. Vale pontuar que usamos o termo "racionalidade" porque, como ressalta Foucault, o neoliberalismo, principalmente aquele baseado no liberalismo norte-americano, é mais do que uma alternativa política, mais do que uma técnica dos governantes em relação aos governados, "é toda uma maneira de ser e de pensar" (FOUCAULT, 2008a, p.301). No contexto neoliberal, as modulações que orientam a construção dos modos de vida derivam predominantemente do mercado. Verifica-se uma intervenção mínima do Estado e a produção de uma sociedade-empresa, conformada pelas dinâmicas estabelecidas pelo mercado de livre concorrência e autorregulador, com regras e dinâmicas próprias segundo interesses privados.

Groppo afirma que a racionalidade neoliberal "traz como resultados nova e enorme lucratividade dos capitais, principalmente os de caráter transnacional e especulativo. Mas, também, novos e assustadores surtos de pobreza, miséria, desemprego estrutural e exclusão." (2007, p.1). Inclusive, crises são pretextos que a governamentalidade neoliberal utiliza para ampliar a atuação do mercado e a privatização das instâncias públicas, a fim de transferir para empresas detentoras de capital financeiro e estrutura administrativa as responsabilidades que não conseguem assumir. Em outras palavras, catástrofes naturais, sociais, crises econômicas são plataformas de governos neoliberais para acelerar a transformação de economias e dinamizar aparatos estatais, entregando ao mercado grande parte da responsabilidade social.

Com efeito, diversas empresas capturam problemas sociais como demandas a serem assumidas como mercadoria de trabalho e divulgadas para conhecimento dos sujeitos de interesse, especialmente seus consumidores, mas também da sociedade como um todo.

A comunicação das marcas é processo ativo nesse contexto. Como já dizia o fotógrafo das campanhas da Benetton, Oliviero Toscani, "A condição humana é inseparável do consumo; neste caso, por que a comunicação que o acompanha deveria ser superficial?" (1996, p.25).

A Benetton (1965), marca de vestuário de origem italiana, exemplifica bem a relação entre mercado e questões sociais. Engajada em diversas causas, a empresa começa a impactar a sociedade na década de 1990, com suas campanhas dirigidas por Toscani. As fotografias das campanhas representam situações ao redor do mundo que a marca acreditava exigir especial atenção. 
No rol das campanhas históricas, a própria empresa destaca algumas:

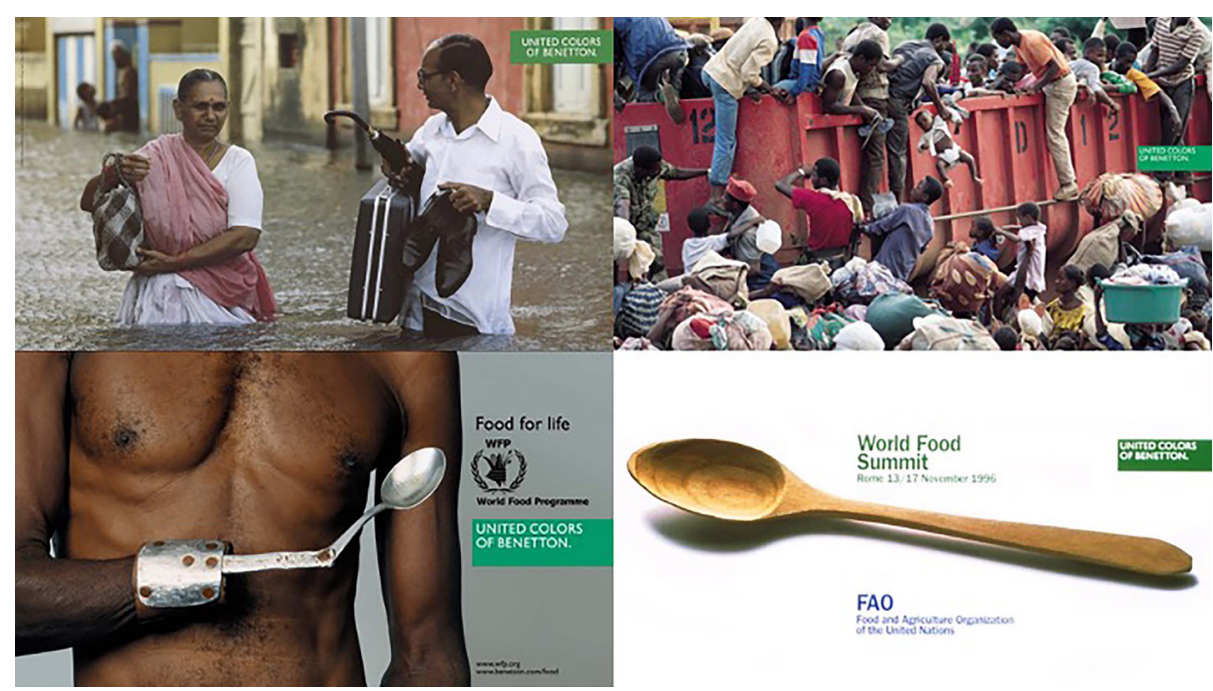

Fig 1. (Topo esq.>dir.) Campanha Benetton 1992 - Flood, Campanha Benetton 1992 - Container: (Baixo esq.>dir.) Campanha Benetton 1996 - Wooden spoon - FAO, Campanha Benetton 2003 Food for Life.

Fonte: http://www.benettongroup.com/media-press/image-gallery/institutional-communication/historical-campaigns. Acesso em: 03/02/2021 [montagem nossa].

A imagem da campanha Flood (1992) apresenta um casal de indianos atravessando uma enchente em Bangladesh. À época, a Benetton visou alertar ao mundo sobre inundações e alterações climáticas cada vez mais recorrentes. Já com a campanha Container (1992), a empresa chamou atenção para os processos migratórios, exemplificada pelos refugiados da Libéria, País africano que enfrentava uma guerra civil.

Em Wooden spoon - FAO (1996), a Benetton juntamente com a $F A O^{5}$, buscou alertar sobre a fome mundial. Nessa campanha, fotografaram uma colher de pau em um fundo branco, que simboliza, segundo a própria empresa, a relação entre a humanidade e a comida, ou a fome, utilizando "a mais simples das ferramentas para evocar o mais antigo dos gestos humanos; colocar comida na boca." (BENETTON, 1996, s/p, tradução nossa) ${ }^{6}$. A campanha Food for life (2003) foi estampada por um homem negro, com a mão amputada e uma prótese metálica com uma colher acoplada. $O$ intuito dessa comunicação foi similar ao da campanha anterior. Junto ao World Food Programme (WFP) - uma das maiores organizações humanitárias de combate à fome ao redor do mundo - a Benetton externou relações entre pobreza e falta de alimentação. 
Importante mencionar que a década de 1990 foi um marco no crescimento das ONGs e Institutos sociais no mundo Ocidental. A eficiência gerada pela estrutura profissional dessas organizações amplia a visibilidade de seus serviços sociais em um momento que coincide com o declínio do Estado em termos de regulação social. Nesta perspectiva, houve crescente interesse do Estado em incentivá-las a cuidar das mazelas sociais. Um exemplo é a empresa holandesa de moda C\&A (1841), que fundou o Instituto C\&A no Brasil em 1991, "com o objetivo de valorizar pessoas e comunidades por meio da promoção de uma educação infantil de qualidade" (INSTITUTO C\&A, 2019, s/p) ${ }^{7}$. Já em 2011 cria a C\&A Foundation (2011) global para "melhorar a qualidade de vida nas regiões em que a $C \& A$ atua, por meio de iniciativas educacionais, de saúde e de ajuda humanitária" (Idem).

Parece possível afirmar que iniciativas como essas, promovidas pela responsabilidade social empresarial, ampliam positivamente a imagem institucional e beneficiam a própria empresa, melhorando seus negócios. Isto é, a empresa aufere lucros diante da ineficiência do Estado. Conforme cita Oded Grajew, ex-presidente do Instituto Ethos: "Não tenho ilusões. A lógica empresarial é o lucro, e não a solidariedade. Mas de repente, há a percepção de que o lucro depende de posturas mais éticas e solidárias. Esta é uma conquista da sociedade civil, e as empresas estão tendo que se adaptar" (1998, p.28).

Esse posicionamento parece ter efeito nos dias de hoje. Pelo estudo global Edelman Earned Brand $2018^{9}$, a agência de marcas e reputação Edelman demonstra que: $69 \%$ dos brasileiros consomem ou boicotam produtos de uma empresa a partir de sua posição sobre uma questão social ou política e $63 \%$ dos entrevistados afirmam que as marcas podem fazer mais para solucionar problemas sociais do que o governo. Quer dizer, os consumidores estão confiando na potência das iniciativas privadas em promover melhorias sociais.

Pelo exposto, nota-se que a forma-sujeito "humanitário" ou humanitarista, é deslocada para uma gama abrangente. Douzinas propõe pensar que o papel do "bom samaritano" é agora desempenhado pelo "capitalista ético", quer seja o empresário benevolente, ou o consumidor filantropo, que acredita na conversão do consumo de mercadorias em benesse social.

\section{Dispositivo moda: 0 engajamento em causas sociais como linha de força}

Desde a década de 1970, o consumo passa a se vincular a questões emocionais e subjetivas - a era do hiperconsumo, em que "as forças do mercado invadem a quase totalidade dos aspectos da existência humana" (LIPOVETSKY, 2007, p.142). O hiperconsumo transcende a era da industrialização do produto e a era onde imperava o volume dos bens adquiridos - fases anteriores observadas pelo filósofo francês Gilles Lipovestky. Mais emocional e subjetiva, a fase do hiperconsumo se caracteriza por uma lógica de que a compra não diz respeito somente a utilidade ou necessidade de um 
item, nem a acumulação de produtos, e sim de vivências, de experiências, de sentidos da vida que o consumo pode trazer. Observa-se, então, que o dispositivo moda está migrando para outros propósitos, muitos dos quais veiculados a um novo tipo de hiperconsumidor, influenciado pelos discursos do consumo consciente.

Nesse sentido, cada vez mais, diversas marcas de moda usam causas sociais em suas ações, como aquelas ligadas aos direitos humanos. Um exemplo de marca de moda que se alinhou a essas questões é a espanhola Balenciaga. Em parceria com o World Food Programme, a grife pretende engajar seus consumidores em causas sociais. Segundo declaração oficial da marca, "Essa colaboração é uma maneira de atribuir uma nova função para a moda, além de ser uma forma de apoiar boas causas com nossos produtos" $(2018, \mathrm{~s} / \mathrm{p})^{10}$. Peças específicas da coleção outono/inverno de 2018 (Figura 2) tiveram $10 \%$ do valor das vendas revertidos para o programa.
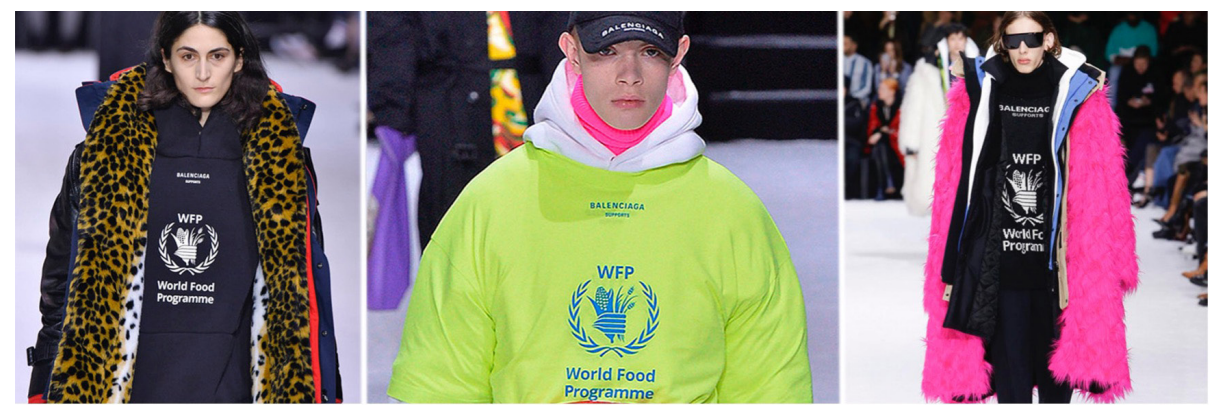

Fig 2. Coleção outono/inverno 2018 Balenciaga.

Fonte: https://www.vogue.fr/fashion/fashion-inspiration/story/from-burberry-to-balenciaga-andlancome-labels-that-support-good-causes/1416. Acesso em: 15/02/2021 [montagem nossa].

A empresa garante que a compra de um boné, por exemplo, proporcionou mais de 200 pacotes de biscoitos para pessoas em situações de emergência, enquanto uma jaqueta corta-vento forneceu kits de alimentação para abastecer 100 famílias. Além dos itens feitos em parceria com o WFP, a Balenciaga doou 250 mil dólares americanos para a instituição. Vale mencionar que a ideia dessa ação veio do diretor criativo Demna Gvasalia, que, segundo a revista Exame (2018, s/p), "vem renovando a marca com seu estilo transgressor e muito alinhado ao discurso das ruas", o que destaca as questões humanitárias quase como uma tendência de moda, que demarca padrões comportamentais é retratada nas passarelas. 


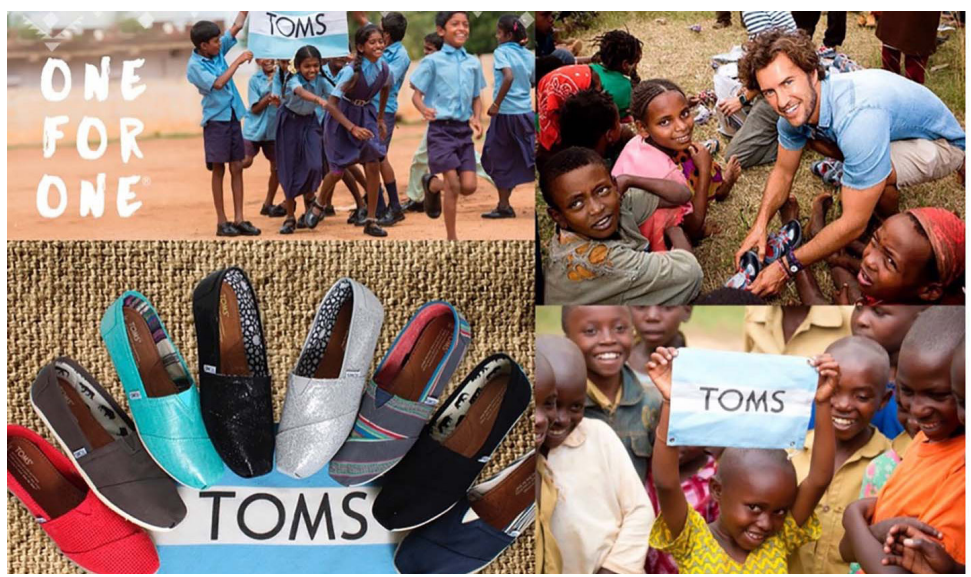

Fig 3. Imagens da marca TOMS.

Fonte: https://www.toms.com. Acesso em: 03/02/2021 [montagem nossa].

No quesito causa social, a empresa de moda que se destaca em nível internacional é a $T_{O M S}{ }^{11}$ (Figura 3). Essa marca de alpargatas criada pelo americano Blake Mycoskie, que inicialmente se chamaria Tomorrow's Shoes (sapatos para o amanhã), trabalha sob o lema "One for One" (um por um): a cada alpargata vendida, outra é distribuída a uma criança em necessidade. Blake acredita que quando se incorpora a doação em um negócio, seus consumidores se tornam mais leais, porque querem compartilhar a história e fazer parte de uma missão ${ }^{12}$. Foi essa ação que transformou a TOMS na primeira empresa de moda a reverter diretamente os lucros em doações.

Mas não são apenas as marcas de luxo que se associam às questões humanitárias; há também grandes magazines. O grupo europeu Inditex, por exemplo, responsável por marcas como Zara, Stradivarius, Bershka e Pull \& Bear uniu-se à fundação Water.org, destinada a doar água limpa e promover o saneamento básico na cidade de Bangladesh na Índia. Importante mencionar que lá, em 2013, ocorreu o desabamento do Rana Plaza, edifício onde milhares de trabalhadores atuavam em condições precárias. Fato que elucida a contradição de se prover auxílio humanitário ao mesmo tempo em que usurpa outros direitos de seus trabalhadores.

Além das marcas que promovem causas sociais, há também outros setores. É o caso de uma semana de lançamentos voltada inteiramente para iniciativas humanitárias. A International Humanitarian Fashion Week (Semana de Moda Internacional Humanitária), aconteceu em 2016 no Canadá, e visou fomentar marcas de moda pelo mundo, com o intuito de ser uma voz global de promoção de direitos humanos por meio de criações artísticas. Essa iniciativa foi criada e sediada pela Unesco (Organização das Nações Unidas para a Educação, a Ciência e a Cultura), agência especializada das Nações Unidas. 
Vale destacar também o Fashion 4 Development (F4D)13, plataforma global do setor privado vinculada à indústria têxtil e de moda. Em 2015, o movimento comprometeu-se a apoiar os Objetivos de Desenvolvimento Sustentável (ODS $)^{14}$, colocando em destaque exemplos de executivos de várias partes do mundo, engajados em filantropia, visando estabelecer uma relação de apoio entre o dispositivo moda e questões humanitárias. Na lista figura um único brasileiro: Rony Meisler, CEO e fundador da marca brasileira de moda masculina Reserva.

A Reserva é um interessante caso a ser exposto. Desde maio de 2016, esta marca operacionaliza seu projeto social denominado 1P5P. A cada peça vendida, a empresa distribui 5 pratos de comida "para quem tem fome" (RESERVA, 2018, s/p). A grife faz o repasse mensal da quantia total para os programas Banco de alimentos ${ }^{15}$ e Mesa Brasil SESC ${ }^{16}$. Estes últimos recolhem e distribuem para instituições assistidas alimentos que seriam descartados. Por sua vez, essas instituições produzem as refeições e alimentam seus beneficiários.

Importante citar que o projeto 1P5P é tomado como parte da "filosofia de gestão" da Reserva, ou seja, pilar de seus valores empresariais. Meisler acredita que a iniciativa privada e a sociedade civil devem atuar ativamente na transformação social, assumindo responsabilidades que são do Estado, como a promoção do bem-estar de uma nação - pensamento que se alinha à racionalidade neoliberal. 0 1P5P é mote de publicidade da Reserva desde quando foi lançado, como mostra a Figura 4, que ilustra algumas comunicações da marca.

Fig 4. Etiqueta externa da marca Reserva com alusão ao 1P5P.

Fonte: https://www.facebook.com/usereserva. Acesso em: 12/02/2021 [montagem nossa].

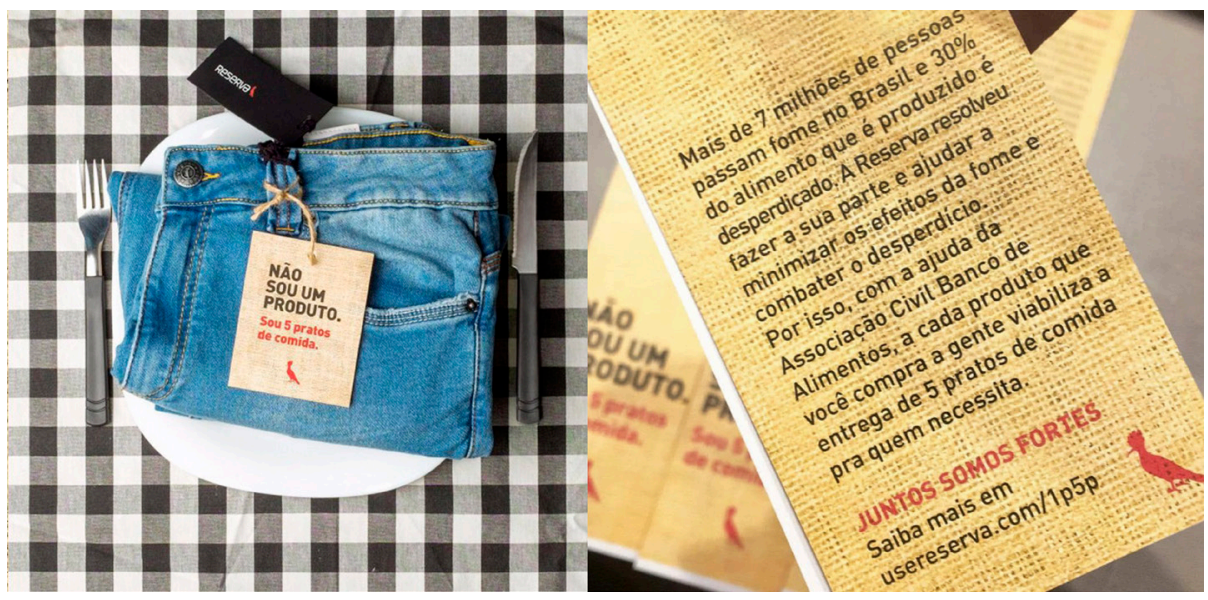

A imagem retrata um momento de refeição: um prato, sobre uma toalha de mesa, ladeado por talheres. $O$ inusitado é uma calça jeans no lugar do alimento e a etiqueta presa à peça, afirmando que aquilo não é um produto, mas sim cinco pratos de comida - já que a venda será revertida em alimento. Esse fato escancara a mercantilização dos direitos humanos, neste caso, direito à alimentação. 
Essa questão também foi vista na ação da marca no São Paulo Fashion Week (SPFW $)^{17}$. Lançado à época da edição de inverno 2017 da SPFW, o projeto e seus ideais foram materializados no convite do desfile da marca, uma marmita de alumínio, mas que em seu interior, ao invés de ter o tradicional arroz e feijão, trazia o aviso de que aquilo "não era um convite de desfile", mas cinco pratos de comida (Figura 5). A Reserva menciona que, ao invés de gastar dinheiro com convites e brindes caros, converteu o valor na doação de alimento em nome do convidado do desfile.

Fig 5. Convite Reserva 1P5P para acesso ao desfile da marca no SPFW Fonte: https://www.lilianpacce.com. $\mathrm{br} / \mathrm{e}-\mathrm{mais} / \mathrm{convite-com-proposi-}$ to-da-reserva-nesse-spfw/. Acesso em: $25 / 02 / 2021$

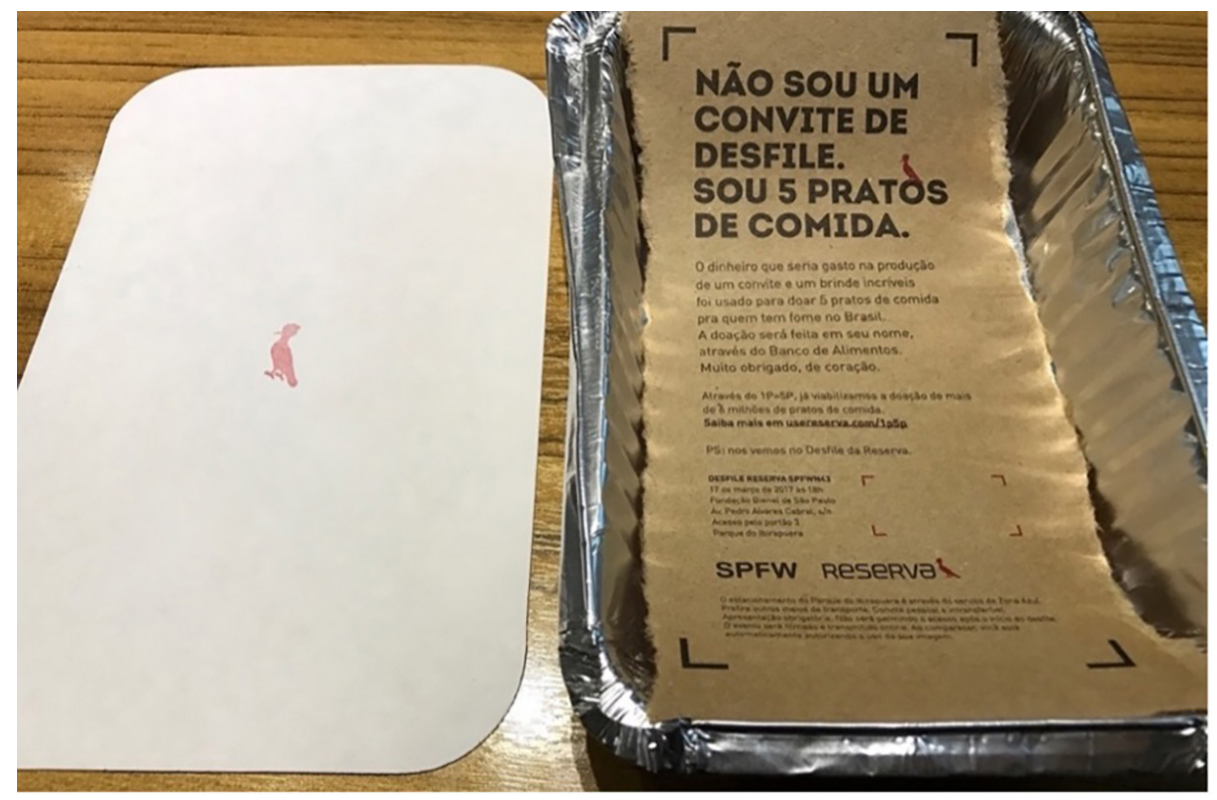

Ainda a respeito do 1 P5P, é importante destacar que quando o cliente realiza uma compra, recebe no cupom de venda, detalhes dos custos do produto: quantos pratos de comida serão doados em razão da compra, além de um agradecimento da empresa. É possível supor que essa prestação de contas, para além das questões burocráticas, também funciona como uma espécie de "certificado de boa ação", tornando a doação visível para o cliente. É notável que possa contribuir para aguçar o desejo de comprar, uma vez que o consumidor se sente satisfeito ao contribuir com uma causa dessa natureza.

Também em 2017, a vitrine de Natal das lojas Reserva foi composta por pilhas de pratos e um adesivo que estampava no vidro o número de doações feitas até então. Foram utilizados elementos ordinários, como os pratos na vitrine, o que contribui para ampliar a dimensão da campanha. 
1P5P foi também o mote principal da marca na Black Friday ${ }^{18}$ do ano de 2017 (Figura 6). Ao invés de viabilizarem cinco pratos de comida para cada peça comprada, dobraram a doação para 10 pratos de comida. Houve divulgação em jornais de grande circulação e pré-campanha em suas redes sociais que apresentou mais sobre o projeto (Figuras 7 e 8).

Fig 6. Campanha 1P5P na Black Friday

Fonte: https://www1.folha.uol.com. $\mathrm{br} / \mathrm{mercado} / 2017 / 12 / 1943970$-acaoque-doa-5-pratos-de-comida-porpeca-de-roupa-vai-beneficiar-alagoas. shtml. Acesso em: 15/02/2021.

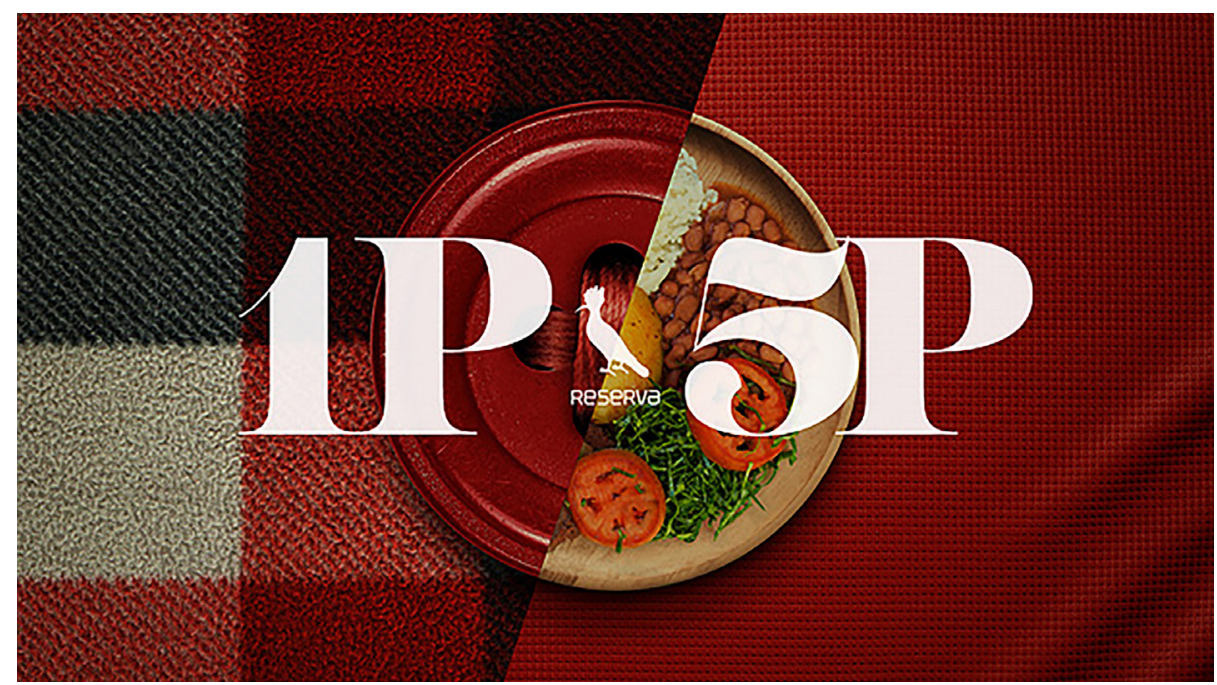

Fig 7. Postagens diárias anunciando o 1P5P em dobro na Black Friday Fonte: https://www.facebook.com/ usereserva/. Acesso em: 04/02/2021 [montagem nossa]

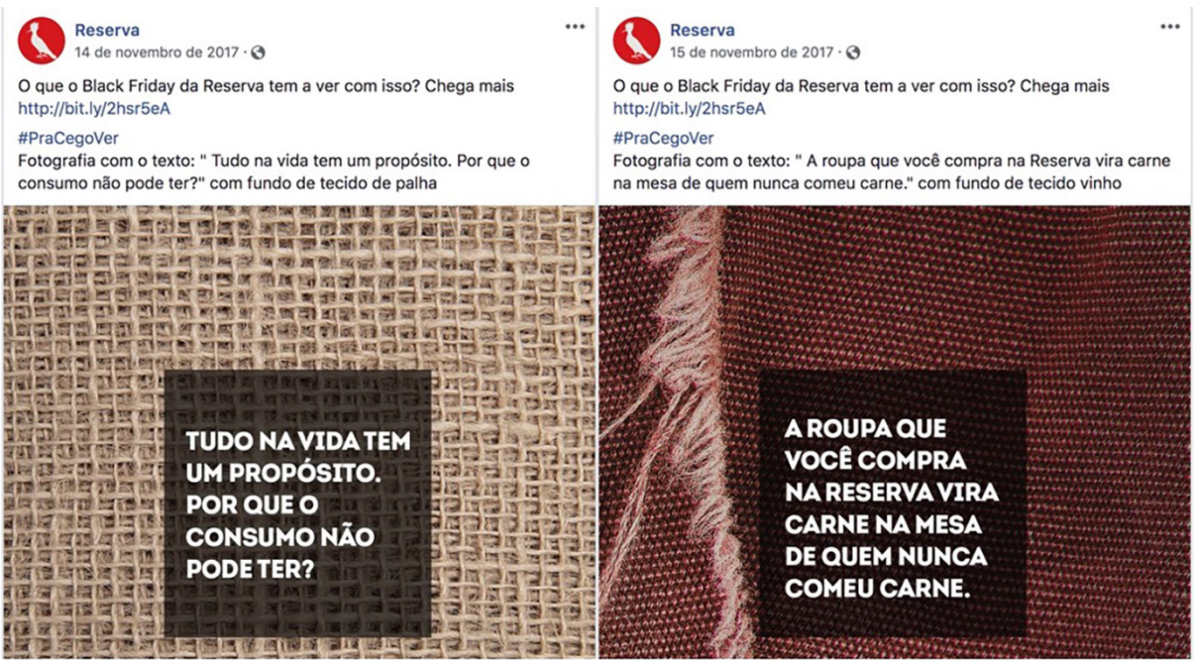

Pode-se observar que as peças publicitárias produzidas para a ocasião, muitas delas postadas na rede social da marca, seguem o padrão de usar um pedaço de tecido como pano de fundo para os enunciados, revelando a conexão entre vestuário, moda e direitos humanos promovida pela Reserva (Figuras 7 e 8). Essa mistura também é vista em algumas frases como "Pretinho básico? Preferimos o prato básico" (Figura 8 ), remetendo-se à uma peça clássica do vestuário amplamente indicada para diferentes pessoas e ocasiões. 
Fig 8. Postagens diárias anunciando o 1P5P em dobro na Black Friday Fonte: https://www.facebook. com/usereserva/. Acesso em: 05/02/2021[montagem nossa].

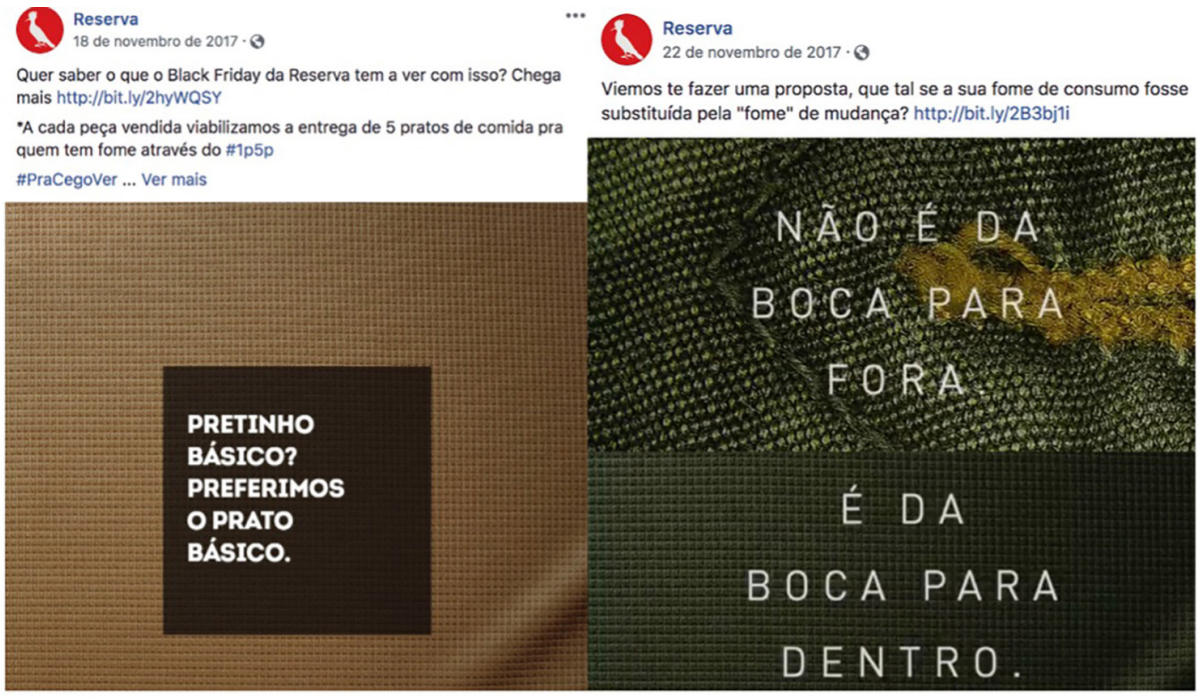

Os enunciados utilizam jogos de palavras e expressões populares: "Não é da boca para fora, é da boca para dentro", faz alusão de que não é só conversa, "papo furado", falácia, a proposta do 1P5P é agir, é alimentar quem tem fome, ou seja, colocar alimento "da boca pra dentro" (Figura 8). A frase "Tudo na vida tem um propósito, por que o consumo não pode ter?", parece validar o ato de consumir se for em prol de causas sociais, convertendo mercadorias em atitudes que beneficiem a sociedade.

Essas comunicações escancaram a mercantilização dos direitos humanos operada pela Reserva, que se destaca também no botão de uma roupa que alude a um prato de comida (Figura 6). Outra vez, a estratégia é de conversão de uma roupa em pratos de comida, reforçando a ideia do 1P5P, a qual também pode ser elucidada pela frase "a roupa que você compra na Reserva, vira carne na mesa de quem nunca comeu carne" (Figura 7).

Ainda em 2017, foi anunciado em um telão de Nova Iorque (EUA), na movimentada Times Square ${ }^{19}$, o comunicado da doação de 5 milhões de pratos (Figura 9), fato que certamente ampliou a visibilidade da marca, seu capital e lucratividade.

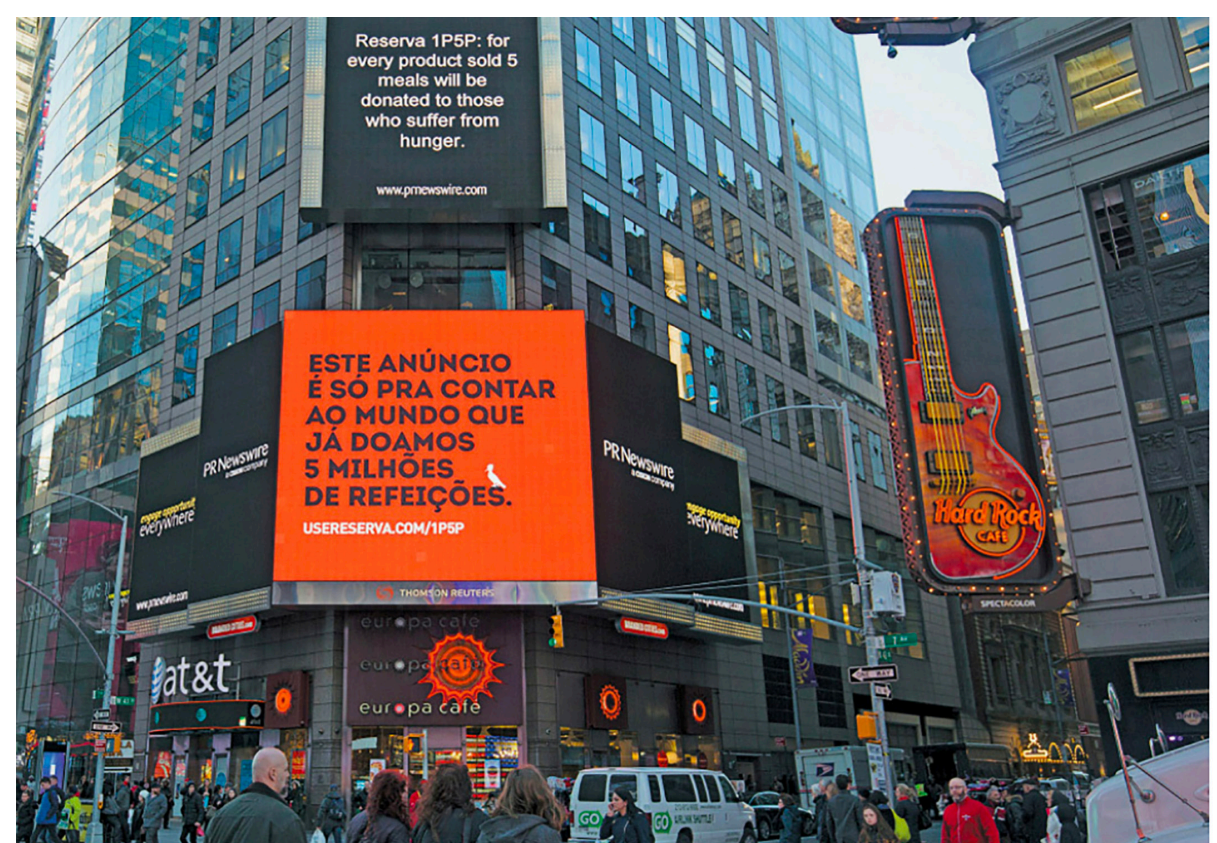

Fig 9. Anúncio na Times Square (Nova Iorque) para comunicar a marca de 5 milhões de pratos doados via 1P5P.

Fonte: https:www.facebook.com/usereserva. Acesso em: 13/02/2021. 
Quadro 1. Comentários de seguidores da Reserva feitos na postagem de Facebook da marca sobre o anúncio na Times Square (Nova Iorque) para comunicar a doação de 5 milhões de pratos. Fonte: Autoria nossa, 2021
- "Eu contribuir muito adquirindo muitas roupas para meu neto" (sic).

- "Por esse e outros motivos eu só uso reserva, que empresa top" (sic).

- "Queria parabenizar a empresa. Acabo de cita-los e mostrar essa história para minha filha de 10 anos. Exemplo de como a iniciativa privada e o voluntariado junto com o mercado fazem bem pra sociedade. Muito mais do que piquete e textaum sobre desigualdade" (sic).

- "Parabéns pela nobreza do gesto. Próximas compras vou priorizar a marca. Isto sim é fazer a diferença e contribuir para um mundo melhor" (sic).

- "Só acho que não precisam jogar na cara!" (sic).

- “Tem coisas que são bonitas e ngm precisa saber, não faça por marketing, faça por amor!" (sic).

Vale mencionar alguns comentários ${ }^{20}$ de seguidores da marca (Quadro 1) na página do Facebook ${ }^{21} \mathrm{em}$ prol de apresentar reações diante da campanha 1P5P, na Black Friday bem como anúncio do balancete dos resultados.

É possível perceber que alguns dos consumidores ficam orgulhosos por comprar produtos e contribuir. Outros expressam que passarão a consumir mais, conhecendo o projeto. Uma pessoa opinou sobre as vantagens. Outros se incomodaram com o marketing baseado numa causa social. Seguindo as lógicas que norteiam o capitalismo contemporâneo, há cada vez mais investimentos de empresas e consumidores na colaboração com o campo social. Na Reserva, o engajamento do consumidor resta claro, pois Rony Meisler (2017, p.389) afirma que junto do lançamento do 1P5P, "coincidências a parte, foram meses de enorme crescimento em faturamento. o bem sempre vence" (idem). Essa informação demonstra que o discurso humanitarista projetado pela Reserva é capaz de impactar e mobilizar os consumidores, consequentemente gerando aumento nas vendas.

\section{Considerações finais}

O humanitarismo é um recurso do dispositivo moda, para se manter lucrativo e renovado, à medida que vai se engajando com as urgências de cada período, como as crises humanitárias. Vale-se de discursos humanitaristas e os coloca em ação, de modo a sensibilizar e atrair o consumidor, como tática para sua preservação no rol dos dispositivos de controle, produtores de modos de vida. Captura a atenção das pessoas, orienta modos de agir, pensar e consumir, influencia condutas, opiniões e discursos.

Nesse sentido, observa-se que nas sociedades de controle, consolida-se um tipo de consumidor desejoso de ser "ético", que muitas vezes corre atrás deste "selo", no consumo de produtos associados às mais diversas 
causas sociais - água para quem tem sede, fim da fome no mundo, ensino para todos e todas, entre tantas outras urgências. Entretanto, repensar os propósitos do consumo parece não representar uma força de combate, mas sim um instrumento de reinvenção da economia mercantil.

Vale enfatizar que não se argumenta pela demonização do consumo. Afinal, se por um lado produz alienação social, por outro é motor de riqueza e desenvolvimento, estimula o trabalho e avanços sociais. Entretanto, transformar o consumo consciente em uma virtude é questionável. Toda ajuda é válida. Contudo, é inegável que quando uma marca, junto de seu capital-clientela, assume o papel de contribuir com faturamento ou qualquer outra via para o combate à fome por exemplo, ela assume o lugar de agente político-econômico-social que deveria ser do Estado. Desse modo, a atuação estatal, que já é mínima - haja vista a própria lógica da racionalidade neoliberal - desaparece ainda mais diante dos desafios sociais que se apresentam. A sociedade civil, a dimensão da vida privada e o mercado ganham espaços que deveriam se manter na dimensão pública.

Observa-se que o consumo engajado em causas sociais pode despolitizar a discussão sobre políticas públicas eficazes e funcionar como agente da desmobilização em muitos casos no sentido de não demandar os direitos que deveriam ser providos pelo Estado, acreditando ser possível obtê-los via mercado. É como se a mercantilização do ativismo humanitário pudesse promover uma espécie de antipolítica, como um paliativo que despotencializa ações efetivas que poderiam agir na estrutura das causas sociais.

Essa questão é tênue entre boa intenção e perversão. Equilibra-se entre conjecturas de responsabilidade social e interesses de produção de dividendos das empresas, pois a mão mercantil que ajuda é a mesma que utiliza o humanitarismo como recurso para produzir lucratividade. A racionalidade neoliberal se faz evidente: das empresas saem doações, ajudas humanitárias que, quando engajadas, são publicitadas. O humanitarismo virou "tendência", todos querem trajar-se e apropriar-se dele.

Neste cenário, os direitos humanos tornam-se moeda de troca e o dispositivo moda utiliza-se francamente da mercantilização do humanitarismo. A retomada histórica e a ênfase no projeto 1P5P da Reserva nos levam a refletir sobre o direito de se alimentar ligado à compra e venda de mercadorias. Nessa lógica, é vital também ter fome de roupa. O que nosso trajeto explicita é a mercantilização do humanitarismo no dispositivo moda. Comprar se converte em "ajudar", esteja o consumidor mais ou menos consciente da ancoragem de sua solidariedade no consumo.

Depreende-se no exposto aqui que há muitas oportunidades de negócio em promover direitos humanos, fato que coopera com o lucro empresarial muitas vezes contínuo e ascendente. Espera-se, com este trabalho, ter lançado um olhar sobre o humanitarismo no dispositivo moda, com votos de contribuir para novas investigações que possam se somar na reflexão sobre o exercício no campo da moda, dentre outros setores, onde o verbo "consumir" é o principal condutor. 
1 "O movimento que vai de um projeto ao outro, de um esquema da disciplina de exceção ao de uma vigilância generalizado, repousa sobre uma transformação histórica: a extensão progressiva dos dispositivos de disciplina ao longo dos séculos XVII e XVIII, sua multiplicação através de todo o corpo social, a formação do que se poderia chamar grosso modo a sociedade disciplinar." (FOUCAULT, 1997, p. 173)

2 Falamos em dispositivo no plural, por esses serem de diversos tipos. Por exemplo, dispositivo sexualidade, que produz formas legítimas e ilegítimas do exercício da sexualidade (FOUCAULT, 1984), também o dispositivo sustentabilidade, que promove o esverdeamento dos sujeitos pelo discurso de consumir produtos sustentáveis (SAMPAIO; GUIMARÃES, 2012), entre outros.

3 Conforme Deleuze propõe, a partir dos últimos escritos do filósofo francês Michel Foucault, as sociedades de controle emergem ao passo que as sociedades disciplinares vão esvaindo-se (DELEUZE, 1992).

4 "O julgamento de Nuremberg [tribunal de julgamento do escalão nazista por crimes de guerra e contra a humanidade durante a 2a Guerra Mundial], é visto como um momento simbólico na criação do movimento de direitos humanos. Direitos humanos emergiram quando a humanidade reconheceu que uma parte comete atrocidades desprezíveis contra a outra" (DOUZINAS, 2007, p.398, grifo do autor)

5 Organização das Nações Unidas para Alimentação e Agricultura.

6 "The simplest of tools to evoke the oldest of human gestures; putting food to one's mouth". Disponivel em: http://www.benettongroup.com/ media-press/press-releases-and-statements/benetton-has-created-the-official-image-of-the-world-food-summit/. Acesso em: 14/02/2021

7 Conforme consta na descrição do Instituto C\&A. Disponível em: https://www.institutocea.org.br/sobre-nos. Acesso: 20/02/2021.

8 "O Instituto Ethos de Empresas e Responsabilidade Social é uma OSCIP (Organização da Sociedade Civil de Interesse Público) cuja missão é mobilizar, sensibilizar e ajudar as empresas a gerir seus negócios de forma socialmente responsável, tornando-as parceiras na construção de uma sociedade justa e sustentável." cf. entrevista concedida à revista Caros amigos, 2(15) junho de 1998, 26-31 "A revolução dos patrões". 9 Em 2018, na quarta edição, a pesquisa Edelman Earned Brand foi realizada no Brasil, China, França, Alemanha, Índia, Japão, Reino Unido e Estados Unidos por meio de pesquisas on-line que ouviram 8 mil pessoas (1 mil por país) e levantamentos feitos pelo celular, com 32 mil pessoas (4 mil por país). Disponível em: https://www.edelman.com/sites/g/ files/aatuss191/files/2018-11/2018_Edelman_Earned_Brand_Brasil_Report_POR.pdf. Acesso em: 11/02/2021.

10 Disponível em: https://exame.abril.com.br/estilo-de-vida/moda-busca-se-engajar-em-causas-da-vida-real/. Acesso em: 15/02/2021.

11 Disponível em: https://www.toms.com/about-toms. Acesso em: 03/02/2021.

12 Disponível em: https://ffw.uol.com.br/noticias/moda/saiba-como-funciona-a-toms-a-marca-de-alpargatas-do-futuro/. Acesso em: 08/02/2021.

13 Disponível em: http://www.fashion4development.com/. Acesso em: 15/02/2021

14 Disponível em: https://nacoesunidas.org/pos2015/agenda2030/. Acesso em: 08/02/2021.

15 "O Banco de Alimentos é uma associação civil que atua com o objetivo de minimizar os efeitos da fome e combater o desperdício de alimentos(...). Os alimentos distribuídos são excedentes de comercialização e produção, perfeitos para o consumo." Disponível em: https:// www.bancodealimentos.org.br/quem-somos/. Acesso em: 05/02/2021. 160 Mesa Brasil SESC é uma rede nacional de bancos de alimentos contra a fome e o desperdício. Seu objetivo é contribuir para a promoção da cidadania e a melhoria da qualidade de vida de pessoas em situação de pobreza, em uma perspectiva de inclusão social. Disponível em: http://www.sesc.com.br/mesabrasil/omesabrasil.html . Acesso em: 04/02/2021

17 Evento de lançamento de coleções moda que ocorre duas vezes ao ano na cidade de São Paulo, no qual marcas brasileiras apresentam - em formato de desfiles - suas respectivas coleções de roupas e acessórios. 
18 Um dia inteiro de descontos, organizado pelo varejo. A ideia foi criada nos Estados Unidos e acontece na última sexta-feira de novembro um dia depois do feriado americano de Ação de Graças, um dos mais importantes do país.

19 Região turística e uma das mais movimentadas de Nova lorque.

20 Apresentados do modo como foi escrito pelas pessoas. (sic) = citação literal do que foi dito por uma determinada pessoa, incluindo os erros gramaticais cometidos por ela.

21 Disponível em: https://www.facebook.com/usereserva/photos /a.255912890572/10158081985800573. Acesso em: 13/02/2021.

\section{Referências}

DELEUZE, Gilles. Post-Scriptum sobre as Sociedades de Controle. In: Conversações: 19721990. Tradução de Peter Pál Pelbart. São Paulo: Editora 34, 1992.

DEYRA, Michel. Direito Internacional Humanitário. Lisboa: GDDC, 2001.

DOUZINAS, Costas. The many faces of Humanitarianism. Parrhesia Journal of Critical Philosophy, no 2, p. 1-28, 2007.

FISCHER, Rosa M. Foucault e a análise do discurso em educação. Cadernos de Pesquisa, n⿳o 114, p.197-223, 2001.

FOUCAULT, Michael. A arqueologia do saber. Rio de Janeiro: Forense Universitária, 2008. FOUCAULT, Michael. Microfísica do poder. Rio de Janeiro: Paz e Terra, 2017.

FOUCAULT, Michael. Nascimento da biopolítica. São Paulo: Martins Fontes, 2008a. GROPPO, Luís. Responsabilidade social empresarial e a mercantilização da solidariedade. Serviço social e Sociedade, no 91, p. 143-162, 2007.

HOURS, Bernard. O espetáculo da desgraça alheia. In: Le Monde Diplomatique, 2008. (http://diplomatique.org.br/o-espetaculo-da-desgraca-alheia).

LIPOVETSKY, Gilles. A felicidade paradoxal: ensaio sobre uma sociedade de hiperconsumo. São Paulo: Companhia das Letras, 2007.

LIPOVETSKY, Gilles. O Império do efêmero: a moda e seu destino nas sociedades moderna. São Paulo: Companhia das Letras, 1989.

MACKEY, John; SISODIA, Raj. Capitalismo consciente: como libertar o espírito heróico dos negócios. São Paulo: HSM Editora, 2013.

MARTINELLI, Antônio C. Empresa-cidadã: uma visão inovadora para uma ação transformadora. In: IOSCHPE, E. B. Terceiro setor: desenvolvimento social sustentado. São Paulo: Paz e Terra, 1997.

MEISLER, Rony; PUGLIESE, Sérgio. Rebeldes têm asas. Rio de Janeiro: Sextante, 2017

PAOLI, Maria C. Empresas e responsabilidade social: os enredamentos da cidadania no Brasil. In: SANTOS, Boaventura de Sousa (Org.). Democratizar a democracia: os caminhos da democracia participativa. Rio de Janeiro: Civilização Brasileira, 2002.

RESERVA. Site da marca Reserva, 2021. (https://www.usereserva.com/).

SERRAL, Isabelle; MESQUITA, Cristiane. Body meets clothes: Fashion Design between normatization and utopia. DAT Journal, no 3, p.52-75, 2019.

SOUZA, Kárida. De mercenários a humanitários: As EMPse as Possibilidades Discursivas do Humanitarismo na Política Mundial. In: 4º Encontro Nacional da Associação Brasileira de Relações Internacionais, 2013.

Recebido: 15 de fevereiro de 2021. SVENDSEN, Lars. Moda: uma filosofia. Rio de Janeiro: Zahar, 2010.

Aprovado: 05 de março de 2021. 